\title{
ARTICLE
}

\section{Therapeutic applications of mindfulness in paediatric settings}

\author{
Carlos Carona, Helena Moreira \& Neuza Silva
}

\begin{abstract}
Carlos Carona completed his
$\mathrm{PhD}$ in clinical psychology at the University of Coimbra, Portugal. He is a consultant clinical psychologist at the Cerebral Palsy Association of Coimbra, and researcher at the Cognitive and Behavioral Center for Research and Intervention, Faculty of Psychology and Education Sciences, University of Coimbra. He also delivers CBT training in postgraduate courses. His clinical and research interests include third-wave CBT, paediatric psychology and developmental psychopathology. Helena Moreira holds a PhD in health psychology (University of Coimbra) and is currently a postdoctoral fellow in clinical psychology at the Faculty of Psychology and Education Sciences, University of Coimbra. Her current research focuses on the applications of third-wave CBT models to understand adaptation processes of parents and their children with chronic health conditions. Neuza Silva completed her $\mathrm{PhD}$ in clinical psychology (family psychology and family intervention) and is a researcher at the Cognitive and Behavioral Center for Research and Intervention, Faculty of Psychology and Education Sciences, University of Coimbra. Her current research is focused on the examination of adaptation processes and outcomes of children/adolescents with chronic health conditions, within a family perspective.

Correspondence Carlos Carona, University of Coimbra, Faculty of Psychology and Education Sciences, Cognitive and Behavioral Center for Research and Intervention, Rua do Colégio Novo - Apartado 6153, 3001-802 Coimbra, Portugal. Email: ccarona@fpce.uc.pt
\end{abstract}

\begin{abstract}
SUMMARY
Mindfulness is a meditation practice defined as a specific way of paying attention. It has been adapted from Buddhist traditions to Western secular use (e.g. in stress reduction, health promotion, treatment of psychological disorders). Despite its widespread application in adult populations, mindfulness remains a neglected topic in the psychological interventions designed for children and adolescents with psychological disorders and/or chronic physical conditions. In paediatric settings, a parent-child perspective may be useful in facilitating processes of adaptation and in improving paediatric outcomes. However, the delivery of mindfulness interventions in paediatric settings raises a number of issues and challenges, which include the developmental appropriateness of mindfulness exercises, the introduction of a parent-child perspective, and specific considerations to condition, treatment and caregiving.
\end{abstract}

\section{LEARNING OBJECTIVES}

- Be able to describe the therapeutic applications of mindfulness in paediatric settings, within a parent-child approach

- Understand age-specific considerations when developing mindfulness interventions for paediatric patients

- Be able to describe the potential benefits of mindfulness practice for parents of children with a chronic health condition or disability

\section{DECLARATION OF INTEREST}

None

Cognitive-behavioural therapy (CBT) has evolved over three waves of psychotherapeutic approaches since its beginnings in the 1950s. The first wave of scientifically based psychotherapy was behavioural therapy, which focused directly on the modification of behaviour and emotion, based on conditioning principles. The second wave was cognitive therapy, as information processing and meaning-making were seen as mediators between stressors and psychopathology, thus implying the therapeutic change of negative thoughts, cognitive distortions, irrational beliefs or dysfunctional schemas, by means of their restructuring (e.g. detection, correction, disputation) and testing. The third wave of CBT represents a fundamental paradigm shift, embedded in postmodernist philosophical theories such as functional contextualism that assumes reality as a dynamic process of continuous change and thought content as largely irrelevant to psychological disturbance (Hayes 2004a; Harrington 2009). Case formulation is especially sensitive to the context and functions of psychological phenomena within third-wave CBT, and treatments highlight contextual and experiential change strategies in addition to more direct and didactic ones (Hayes 2004a).

Although there is no consensual classification of which psychotherapeutic approaches constitute 'third-wave CBT', there seems to be considerable agreement on including dialectical behaviour therapy (Linehan 1993), acceptance and commitment therapy (Hayes 1999) and mindfulness-based cognitive therapy (Segal 2002) under that umbrella term (see Öst 2008; Kahl 2012). Among the common features shared by these therapies (e.g. the focus on mindfulness, acceptance, the person's values in life), mindfulness is arguably the most cross-cutting characteristic. In this article, we aim to illustrate the potential therapeutic applications of mindfulness to paediatric health contexts - in the most general sense of encompassing paediatric psychological disorders and chronic physical conditions, and as targeting parents' and their children's needs - and to provide clinical guidelines for effectively conducting mindfulness-based interventions in paediatric settings. The article starts with a functional definition of mindfulness and its spectrum of therapeutic indications, followed by the presentation of essential guidelines and clinical examples for mindfulness in practice, while applying a dyadic parent-child approach to mindfulness-based intervention strategies and processes.

\section{What is mindfulness?}

Mindfulness has been defined as 'paying attention in a particular way: on purpose, in the present moment, and non-judgmentally' (Kabat-Zinn 1994; p. 4). In clinical terms, mindfulness is perhaps best 
understood as the 'awareness that emerges' from the process of nurturing three interrelated skills (Williams 2008; p. 721):

- intentionally paying attention to moment-bymoment events, as they unfold in the internal (i.e. mind and body) and external world

- noticing one's immediate, often impulsive and repetitive reactions to those events that tend to elicit aversion or fixation, which in turn are likely to result in maladaptive behaviours, such as avoidance and rumination

- adopting an attitude of open curiosity and compassion directed at the events and one's reactions to them.

Accordingly, the phenomenology of mindfulness as a moment-by-moment process embodies a single, interdynamic relationship between three conceptual pillars or axioms: intention, attention and attitude (Shapiro 2006). However, two additional observations are especially noteworthy for the axiom of intention. The first is that 'intention' may be applied, in a strict sense, to the volunteer nature of the mindful way of paying attention (i.e. one is aware of where the attention is focused, and then willingly redirects it), and in a broader sense, to the motivations underlying the practice of mindfulness (e.g. the intention for practising mindfulness may be the achievement of greater self-regulation, self-exploration or selfliberation) (Shapiro 2006). The second observation clearly distinguishes the volunteer nature of paying attention from aiming to control attention itself: during mindfulness exercises involving the redirection of attention, when one is noticing where their attention is directed (e.g. an intrusive thought) and wants to pull it back to another event (e.g. the soothing physical sensations of breathing), this will be done in a most kind and gentle tone (e.g. 'Ah, there you are... come here again...'), as opposed to a cold and coercive tone (e.g. 'Just focus on this!', 'Stay there!', 'Don't go that way!'). The rationale for this is strongly supported by the counterproductive effects of thought or mood suppression, simply because our thoughts and emotions are not amenable to verbal ruled control. From this perspective, willingness is the alternative to control (Hayes 1999). In fact, mindfulness inherently embraces 'an affectionate, compassionate quality within the attending' (Kabat-Zinn 2003; p. 145).

A negative operational definition of mindfulness may be helpful in applying the concept for reframing a number of daily and clinical situations. Examples of such mindlessness behaviours include: pressing the elevator's button incessantly to make it arrive faster; shouting at children to teach them that shouting is not appropriate; tormenting oneself over the remaining daily agenda, while being stuck in the hospital waiting room; eating when one is no longer hungry; or speaking to children or adolescents using an intimidating tone with the intention of reducing their anxiety or increasing their compliance.

\section{Mindfulness put into clinical practice}

Although its origins are founded in Buddhist meditation practices, mindfulness has been adapted for secular use in Western societies, namely in stress reduction and mental health settings. In this sense, even if mindfulness tends to be typically linked with meditation, the point of view endorsed here is that any technique that increases attention to the present moment and an attitude of acceptance is to be considered a mindfulness technique (Hayes 2004b). In fact, mindfulness can be developed with the therapeutic training of 'psychological and behavioural versions of meditation skills usually taught in Eastern spiritual practices', which are essentially centered on 'observing, describing, participating, taking a nonjudgmental stance, focusing on one thing in the moment, being effective' (Linehan 1993; p. 114).

These core mindfulness skills may be grouped into 'what' and 'how' skills. The 'what' skills include: observing (i.e. noticing, paying attention to experience); describing (i.e. labelling experience with words); and participating (i.e. focusing full attention on current activity). The 'how' skills encompass: accepting without evaluation (i.e. nonjudgementally); behaving with undivided attention (i.e. one-mindfully); and doing what works (i.e. effectively). Box 1 presents a series of exercises targeting each of these core techniques, which can be performed while developing mindfulnessbased interventions for paediatric patients and/or their parents.

\section{How mindfulness works}

There is now widespread evidence for the efficacy of mindfulness-based therapy for a variety of psychological problems (especially stress, depression and anxiety) across physical/medical conditions, psychological disorders and non-clinical populations (Khoury 2013). From a behaviourist point of view, these beneficial effects of mindfulness are explained through the process of modifying the stimulus functions of internal experiences, such as the ways people react to their thoughts, feelings, bodily sensations and urges. Specifically, the following mechanisms have been formulated to explain how mindfulness training results in therapeutic change (Baer 2003; Shapiro 2006). 
B0X 1 Exercises for developing core mindfulness techniques for paediatric patients and/or their parents

Observing

Key point

Noticing the experience without reacting to it; developing a 'Teflon mind' (i.e. thoughts may come and go, without sticking to your mind)

Examples:

- the movements and sensations of breathing

- tastes, sensations and movements while eating

- sounds, scents, textures

- what one can see around one

- urges (e.g. to scratch an itch, to change one's sitting posture)

Describing
Key point
Labelling, applying words to the things one
observes; realising that the mind is not the reality
and it has a life of its own (i.e. thoughts are
thoughts, feelings are feelings)
Examples:
- labelling of internal experiences (e.g. 'I am
having the thought that I am different', 'A feeling
of despair has just come to me')
- objectively describing the things one sees around
(e.g. trees, paintings, animals, people passing by)
- identifying sequences of events and feelings
(e.g. 'My boyfriend didn't call me on time and I
got annoyed', 'My child started yelling and I felt
embarrassed')

Participating

Key point

Immersing oneself in the present moment, in the current activity - the opposite of doing things on 'automatic pilot' (i.e. mindlessly); it can be practised with any activity

Examples:

- playing a tabletop game

- singing, dancing, listening to music

- practising sports, physical exercise

- having a shower/bath

- studying, reading

- conversation
- Re-perceiving and decentring: mindfulness involves a crucial 'shift in perspective', by enabling the individual to approach their internal and external experiences with greater distance, clarity and broadening of attention.

- Exposure: mindfulness encourages a nonjudgemental attitude towards negative emotional states, thoughts and urges, thus counteracting the individual's attempts to avoid those states, which often result in increased distress.

- Reducing dysfunctional psychological processes: mindful acceptance of thoughts and affective states is an effective alternative to counterproductive efforts to gain control over those experiences, such as rumination or thought suppression.

- Increasing adaptive psychological processes: mindfulness implies the acknowledgement of the universality of human suffering, and thus may be regarded as an act of loving kindness directed towards oneself (i.e. self-compassion). In addition, mindfulness decreases emotional and behavioural reactivity to unpleasant events (often linked to ineffective outcomes and selfcriticism), while allowing the individual to respond to such events in agreement with their goals and valued living directions.

\section{Therapeutic indications of mindfulness in paediatric settings}

Mindfulness-based interventions are currently implemented in a variety of health contexts to address 'universal vulnerabilities': 'those mental or behavioural habits that undermine well-being and maintain chronic feelings of dissatisfaction because of certain universal aspects of being human: having language, taking such language literally, using thought-based processes to elaborate, solve or escape from problems, and persisting in using such strategies even if these do not solve the problem' (Williams 2008; p. 722).

The applications of mindfulness to the treatment of psychological disorders (including child and adolescent psychopathology) encompass the following psychopathological dimensions: mood (anxiety and depression); intrusions (ruminations, hallucinations and memories); behaviours (binge eating, addiction, self-harm and violence); problems of relating (attitudes and empathy); and problems of self (self-consciousness and selfhatred) (Mace 2007).

In addition to the intervention needs of children and adolescents with mental disorders, we gained insights from our clinical and research practice that broadened the spectrum of therapeutic indications of mindfulness in paediatric settings to include the difficulties and challenges experienced by children with chronic physical conditions and their parents (or other family caregivers). We strongly endorse a classic recommendation for paediatric training (Allmond 1979), while asserting that any paediatric clinician has to be cognisant of the fact that they will be almost always working with (at least) two patients simultaneously - a child and a parent. Potential indications of mindfulness for paediatric patients with chronic physical conditions, as well as their parents, are listed in Box 2.

\section{Developmental considerations}

From a developmental perspective, if it seems unhelpful to regard children as 'little adults' (Thompson 2008), then one may equally assume the inadequacy of approaching adolescents as 
'grown up children' (Carona 2013a). In fact, children and adolescents have distinct cognitive abilities and face different maturation issues and developmental tasks. Accordingly, the exercises delivered in paediatric mindfulness-based interventions have to be adapted to fit different ages and their corresponding abilities. There is no consensus on the age from which mindfulness might be delivered to children: on the one hand, there are exercises available for children aged 5 years (Snel 2013); on the other hand, some authors have endorsed a Piagetian perspective in arguing that mindfulness would be impracticable before the attainment of the 'formal operations' stage (i.e. from around the age of 12), where abstract and hypothetical reasoning is achievable (Wagner 2006). Given the current state-of-the-art on the feasibility of mindfulness-based interventions with children, and based on our own clinical experience, we support the idea that clinically meaningful work is viable with children within the 'concrete operations' stage (i.e. from around the age of 7 to 12). From this stance, a number of clinical guidelines (see Semple 2006; Thompson 2008; Silverton 2012) gain special relevance for improving the effectiveness of mindfulness-based interventions with paediatric patients.

- Attention and memory abilities are less developed in younger children, so therapeutic sessions should be briefer and include more repetition.

- Children have limited verbal fluency and abstract reasoning, and therefore intervention protocols should include greater variety of games, practical activities and storytelling.

- Like many adults, children and adolescents may have difficulties in linking the relevance of mindfulness exercises to their daily difficulties, which calls for greater explanation and discussion of the rationale.

- The use of age-related metaphors is to be highly valued (e.g. cartoons, pop music videos or situations seen in football/other sports).

- Children's development is largely shaped by their family environment, which implies that it is important to promote parents' involvement in mindfulness-based intervention processes.

Box 3 presents a summary of key messages for ensuring the developmental validity of mindfulness-based therapy with paediatric populations.

\section{Mindfulness exercises for children and adolescents}

The use of metaphors in paediatric mindfulnessbased therapy is valuable not only in illustrating the explanation of the rationale for intervention,

BOX 2 Therapeutic indications of mindfulness for paediatric patients with chronic health conditions and their parents

\begin{tabular}{ll}
\hline Children & Parents \\
- Psychological comorbidity & - Psychological morbidity \\
- Coping with disease- and treatment- & - Caregiving burdens \\
related stressors & - Modification of child's problem behaviour \\
- Therapeutic non-adherence & - Work-family conflict \\
- Paediatric pain management & - Caregiving gratifications, meaning-making \\
- Lifestyle-related exacerbating behaviours & and personal growth
\end{tabular}

but also in guiding and developing the intervention process itself. Age-appropriate metaphors are useful means of translating abstract ideas or concepts into concrete terms that are easily understood by children. Here are some examples of metaphors that we have found especially useful in clinical practice.

\section{The possibility of radical acceptance (Ciarrochi 2008)}

This metaphor comes in the form of visual analogy, using a sequence of three funny cartoon scenes, which may be applicable to school-aged children, adolescents or adults. In the first scene, a battle between a man and a monster is presented in the form of a 'tug of war' (i.e. the fight of the individual with their own negative emotions, such as fear). The second scene portrays the exhaustion of both sides after a period of battle (i.e. the counterproductive effects of the efforts to control or avoid intrusive thoughts or negative emotional states). In the last scene, we see the individual inviting the monster to come along with him, and the monster assuming a manageable, even reluctant attitude (i.e. thoughts and emotions may 'calm down' if one just accepts them as part of a situation and of life itself).

B0X 3 Key messages of a developmental approach to mindfulness in paediatric settings

- Keep exercises brief: a rule of thumb is 1 min of mindfulness practice for each year of age

- Start gradually: start with bringing attention to concrete stimuli of the external environment, then move to the sensations of the body, and finally introduce meditation exercises with attention directed to the mind

- Be flexible as well as developmentally appropriate: not all 5-year-olds can do guided meditation for $5 \mathrm{~min}$, nor all children achieve the practice of sitting meditation
- Play, play and play: playing is a natural source of children's enjoyment, openness and curiosity - which is exactly what is encouraged in mindfulness. Whenever possible, involve parents in these playing activities

- Be fun and creative: you do not need to adopt a 'guru attitude'; talk in a compassionate manner with the child/ adolescent and their family, develop your own metaphors or exercises, and use humour abundantly 


\section{Mindfulness and mindlessness outside the therapy room (Thompson 2008)}

This illustration of rationale for intervention simply involves the humorous discussion of daily situations where we realised that we were getting 'mindless' (e.g. suddenly realising we are exhausted or need to go to the toilet; being in the heat of a dispute with our girlfriend/boyfriend, without remembering how it started). The link between mindfulness exercises in the therapy room and the outside world can also be illustrated by the need of pop singers and top football players to concentrate and practise in private in order to give astonishing performances in public.

\section{The mindful warrior (Ciarrochi 2012)}

The 'cool' image of a 'mindful warrior' (similar to that of a samurai or a ninja) conveys a sense of courage and energy, and may make the invitation for learning mindfulness rather appealing to adolescents. Moreover, it is argued that mindful warriors are 'BOLD' (Ciarrochi 2012; p. 10) - an acronym that synthesises the core mindfulness skills to be developed: 'Breathing deeply and slowing down', 'Observing', 'Listening to your values' and 'Deciding on actions and doing them'.

\section{Practical exercises}

In addition to metaphors, practical exercises are needed for the experiential development of core mindfulness skills in paediatric patients (see clinical illustrations in Boxes 4 and 5). ${ }^{\text {a }}$ The following are some examples that we have found both effective and funny.

\section{The fruit game (Silverton 2012)}

This game can be played with children, adolescents and adults. Ideally, you play it in the therapy room with parents and their child, but it can also be performed with small groups of children. You will need a lemon (or other fruit/ vegetable, such as a tangerine or potato) for each participant. First, ask all players to close their eyes, preferably also using a scarf or a kerchief as a blindfold. Second, participants take one lemon each and examine it carefully, feeling its size, shape and texture, smelling it and even tasting it. This can last around $3 \mathrm{~min}$ and may be guided by your instructions. Third, collect all of the lemons and mix them up in a bowl. Finally, invite each participant to identify their particular lemon. As noted by Silverton (2012), most of us would tend to expect that we would never find 'our lemon'; however, through the mindful use of our senses, we become very familiar with 'our lemon' and it is often easy to identify.
Animal breathing (Race 2013)

This exercise is especially tailored to younger children and aims to teach them the importance of breath and breathing, through the imitation of breathing of various animals. It can be completed with a good storytelling (or reading) and it is helpful for developing mindfulness skills while having a good laugh. Examples include, but are by no means restricted to, the following: 'bumblebee breath' (i.e. inhaling through the nose, then exhaling with a humming sound by putting the lips together); 'snake breath' (i.e. inhaling through the nose, and then making a prolonged hiss with the teeth together); and 'lion breath' (i.e. inhaling through the nose, then exhaling through the mouth, with one's tongue hanging out). The additional ideas of developing 'wolf breath' or 'bear breath' are just a matter of creativity and improvisation: the key message here is for children to develop awareness over the usefulness of a deep and slow breath.

Choosing not to listen to the mind machine/never mind my mind (Ciarrochi 2008)

Originally proposed as a self-help guide for adolescents, this exercise is useful for addressing the core mindfulness skill of 'describing'. First, the adolescent is asked to recall situations where their mind was telling them one thing, but where they often did the opposite (e.g. mind urging you to lose control, like hitting or insulting someone, but you chose not to comply; mind telling you that you would fail the exam, but you sat it anyway and got a good mark; mind repeating that you were too tired or bored to study or go out, but you did it anyway). Then, the adolescent is taught to label their thoughts in a practical, even jokey way: 'Ah, there you are again, long time, no see! - I'm having the thought that I'm worthless' or 'Thank you, Mind, for telling me once again that I will fail at school'.

\section{Mindfulness exercises for parents}

Although caregiving is an essential component of normative parenting, the demands and strains of caring for a child with a chronic health condition or disability may be over and above those experienced by parents of a typically developing child. Positive and negative psychological states are likely to cooccur during caregiving, and the experience of positive emotions in that context may facilitate meaning-based coping (i.e. positive reappraisal, problem-focused coping, and creation of positive events) and sustain adaptive coping mechanisms (Folkman 1997). In this context, intentional mindfulness has been recommended to generate 
positive emotions in parents, which then 'broaden and build' their coping repertoires and resources (Larson 2010). Indeed, there are a number of clinical guidelines for the conduct of mindfulnessbased psychotherapy with parents (Carona 2013b). Mindfulness exercises developed in third-wave CBT for adults (Wells 2006; Williams 2011) may be suitable and easily adapted for the parents of children with chronic health conditions, and here we provide complementary therapeutic exercises and techniques that we have found particularly effective when working with parents. Within a parent-child perspective, parents may often assume the role of 'proto-therapists', although mindfulness-based interventions may be used for parents' direct benefit and for improving the parent-child relationship and interactions.

\section{Socratic questioning}

Socratic questioning is one of the most classic methods in CBT. Interestingly, this method of guided discovery has been adapted for promoting mindful acceptance in the context of third-wave CBT (Ciarrochi 2008). Here are some questions that may be useful in developing a mindfulnessbased Socratic dialogue:

- What have you been struggling with?

- How have you tried to overcome that?

- How did those efforts work out? (in the short-term and afterwards)

- What have you given up because of these difficulties?

- Why is it so hard to change your thoughts and feelings?

- If trying to change your thoughts and feelings does not work, then what can you do?

- What are the other ways out besides the one you keep avoiding or struggling with?

\section{Broad-minded affective coping}

In addition to increased caregiving burdens, parents of children with chronic health conditions may have a limited experience of caregiving uplifts or gratifications, which are likely to serve as important stress buffers (Carona 2013b; Silva 2015). Although primarily described as a positive CBT tool (Tarrier 2010), broad-minded affective coping (BMAC) has been suggested to improve the focus of attention, improve emotional regulation and increase awareness of how attention affects emotions (Johnson 2013). From the theoretical standpoint adopted in this article, BMAC may be regarded as a therapeutic technique addressing the development of mindfulness skills. Although its intervention rationale and procedure are
BOX 4 Case vignette: John, 9 years old
John was referred to therapy because of his difficulties with staying quiet and concentrating, especially at school, and physically aggressive behaviour directed at his peers. By the end of the first semester, a second retention in the 4 th grade was a plausible scenario. In the first therapy session, the therapist found John so reluctant to remain seated that he invited the boy for a walk around the clinic gardens - which he readily accepted. After talking a little bit about John's likes and dislikes, the therapist invited John to play a game with him, which was simply to stay quiet and pay full attention to all sounds around them (the winner would be the one to notice more sounds). John enjoyed the competitive tone of the invitation, remained quiet for more than $2 \mathrm{~min}$, and actually surpassed the therapist in recalling different sounds.

In the next session, the therapist invited John to role-play with him the fighting he had been involved in during the morning. When the therapist was playing 'the other guy', John was asked to scan for any body sensation or reaction, which could serve him as a signal that he was 'under heat' and about to lose control. John immediately raised both his hands fisted. Without trying to modify that reaction, John was encouraged to notice his fisted hands as signal of energy and determination, which he could direct to other actions instead of hurting his peers and ultimately himself. The image and attitudes of Cristiano Ronaldo in the football field (of whom John was a huge fan) served to illustrate the purpose and importance of non-reacting and concentrating on one's will (e.g. 'How does he react when under pressure?', 'How does he react when a referee acts unfairly?').

In the following sessions, a number of games were used to foster non-reaction to urges and attention to the present moment. John's mother participated in some of these games, and later commented that she could not recall the last occasion she had enjoyed such pleasant and rewarding moments with her son. Throughout the therapeutic process, John abandoned his aggressive behaviour towards his peers and improved his academic performance to the point of passing to the elementary school with no poor grades.

\section{BOX 5 Case vignette: Peter, 16 years old}

Peter was referred to therapy by his dermatologist because of low self-esteem and high shame and self-criticism. He had a medical diagnosis of acne, which skin-picking. In therapy sessions, especially when talking about anxiogenic issues, Peter would engage in skin-picking, which sometimes even resulted in bleeding. Whenever the therapist called the boy's attention to his self-injuring behaviour, he would stop for a moment and reply: 'I just can't help it'. The therapist then asked Peter to state a few things we all tend to do in our daily routines without even thinking about them - i.e. we just do them. To develop his awareness over his 'automatic pilot' mode, Peter was asked to teach his therapist walking, imagining that he had never walked before. Peter was then asked to reflect on the different components that constitute the most common, spontaneous behaviour: for walking, one would need to lift one foo was getting more severe because of his from the floor, move it forward, and then put it back on the floor again. Afterwards, Peter was challenged to deconstruct his 'unavoidable' skin-picking into 'steps': first, to notice an itching or uncomfortable sensation on the skin; second, to lift his arm and take his hand to the skin; third, to touch and search for the pimple; fourth, to start squeezing or scratching the pimple; fifth, to keep on squeezing, picking and scratching; and sixth, to stop skin-picking after seeing the blood in his fingers. By doing this, Peter was able to develop awareness of his movements related to skin-picking: every time he noticed an itch or other would 'take two steps back' and then softly pose his hand on the affected area of the skin, just touching it, to alleviate the itch. When itching was not present, he became able to stop any movement of the hand to search for and squeeze the pimples. uncomfortable sensation on his skin, he

described elsewhere (Tarrier 2010), a general

outline of BMAC is presented in Box 6. 
B0X 6 General outline of the broad-minded affective coping technique

\section{Preparation}

To achieve a relaxed state that will facilitate the experience of positive emotions, patients are asked to perform a simple autogenic procedure, followed by focusing their attention on breathing (alternatively, a breath and body meditation can be used (Williams 2011)).

\section{Guided imagery of positive memories}

Patients are asked to recall a specific memory of a positive event (which has been previously discussed with the clinician) as clearly and vividly as possible. To achieve this, the clinician will prompt with a series of questions of details of the situation (this can be done quietly). Sometimes this can be best achieved by guiding the patient to 'look around' their memory and its details.

\section{Engaging the senses}

Once the vivid mental image has been created, the patient is asked to recall any other sensory input, including smells, noises, textures and even tastes. Sometimes it is useful to ask about the weather (e.g. 'Can you recall the sun on your face?') or loved ones (e.g. 'Can you recall the smell of your child's hair when you hug her?')

\section{Re-experiencing the associated emotion}

Patients are now asked to recall their inner, emotional experience at the time. This process of identifying and labelling emotions can be facilitated with prompting from the clinician.

\section{Interrogate the memory}

This final stage is aimed at developing the patient's awareness over their interpretations and appraisals that resulted in the positive emotion. Therefore, patients are prompted to ask themselves what made them feel happy, proud, peaceful or cheerful The clinician may then rephrase quietly the patient's associations to reinforce their awareness.

\section{Feedback and debriefing}

After performing the exercise (nearly $20 \mathrm{~min})$, patients are gently asked to open their eyes and to stretch. Patients are asked how they feel now and how they felt throughout each stage of the procedure. The subjective experience of the patient and the applications of the procedure are discussed. Practice outside the therapy room is encouraged.

Adapted from Tarrier (2010) meditation practices (e.g. body scan meditation, loving-kindness meditation, mindfulness of the breath, sounds, emotions and thoughts), consistent with the theme of each session. In addition, parents are encouraged to practice meditation and other exercises between sessions and, when appropriate, in the interactions with their child. To illustrate the practice of mindfulness in the interpersonal context of parent-child relationships, an exercise from this course is briefly described in Box 7 .

\section{Practical issues in delivering mindfulness- based interventions}

There are different perspectives on the issue of clinicians' personal practice of mindfulness and the delivery of mindfulness-based therapy. Some approaches suggest that it is imperative to continue personal practice of mindfulness and to seek supervision: 'mindfulness [...] cannot be taught to others in an authentic way without the instructor practicing it in his or her own life' (Kabat-Zinn 2003; p. 149). Other models place an emphasis on the clinician's mastery of mindfulness skills, based on their empirical learning (Dimidjian 2003). In any case, a deep knowledge of mindfulness practice seems essential for a clinician to give appropriate guidance and respond compassionately to patients' difficulties during the implementation of mindfulness-based interventions. We therefore suggest that clinicians willing to teach mindfulness to their patients should themselves take heed of the following requisites:

- experiential training or supervision on mindfulness practice

recently proposed approach to parenting that can be defined as a set of parental practices or skills that seek to enhance moment-to-moment awareness in the parent-child relationship. Specifically, mindful parenting encompasses five core elements (Duncan 2009):

1 listening with full attention to the child

2 adopting a non-judgemental acceptance attitude towards the self and the child

3 developing emotional awareness of the self and the child

4 exerting self-regulation in the parenting relationship

5 directing compassion for the self and the child.

Bögels \& Restifo (2014) proposed a mindful parenting course targeted at parents who are under conditions of high stress (e.g. conflicting parent-child relationship, parental or child psychopathology). In each session, parents are instructed to complete several exercises (e.g. gratitude practice, imagination exercises, holding strong emotions with kindness) and formal
BOX 7 Parenting stress exercise: bringing kindness to yourself

- After closing their eyes, parents are instructed to imagine as vividly as possible a stressful interaction with their child

- After imagining the situation, parents notice how they are feeling in the present moment (bodily sensations, feelings, thoughts and emotions)

- Parents are encouraged to bring an attitude of selfcompassion by comforting themselves physically (e.g. putting their hands over their heart or placing their arms around their shoulders) and/or in their inner dialogues (by saying to themselves, for instance: 'This is a difficult moment', 'I try hard to be a good parent but sometimes it may be very difficult')

- Parents are guided to remind themselves that all parents fail and make mistakes and that all humans are imperfect

Adapted from Bögels (2014) 
- deep knowledge of the theoretical models supporting the incorporation of mindfulness in psychotherapy

- ability to establish compassionate therapeutic relationships based on mindfulness-related skills and attributes

- a regular update of the scientific developments of mindfulness therapeutic models and interventions.

Perhaps as important is the suggestion that mindfulness may be a promising context for promoting paediatric healthcare that is compassionate. In fact, the term 'total care' has been coined to describe a model of care that encompasses the physical, psychological, social and existential dimensions of pain and suffering of patients and their caregivers (Halifax 2011).

\section{Future directions in research}

Mindfulness research in adult populations has flourished over the past couple of decades; however, the empirical study of its applications with children and adolescents is still in its infancy. As might be expected, the first studies conducted in this area were aimed at ascertaining the feasibility of mindfulness-based interventions for children and adolescents; although this was ultimately established, those studies gathered limited empirical evidence of the efficacy of these interventions (Burke 2010). More recently, the number of studies targeting paediatric populations (often implying a parent-child perspective) has increased, with promising evidence for the feasibility and efficacy of mindfulness-based interventions in a number of conditions such as HIV infection, Asperger syndrome, substance misuse, attention-deficit hyperactivity disorder, depression and conduct disorder (Singh 2007; Harnett 2012). Furthermore, there is growing complementary evidence for the efficacy of mindful parenting intervention programmes in promoting a more positive parent-child relationship, the quality of parenting, and the psychological functioning of children and parents (Harnett 2012).

Currently, mindfulness-based interventions are generally regarded as a feasible and effective method of developing resilience and in the treatment of disorders in paediatric populations (Greenberg 2012). Nevertheless, for advancing the state of knowledge, the following research directions are highlighted. First, there is a need for randomised controlled clinical trials of defined intervention approaches. Second, the contributions from developmental psychology should be valued and incorporated in paediatric psychology research. Finally, the study of mechanisms of change and intervention outcomes could be improved with the simultaneous examination of intrapersonal (i.e. 'self in process', for example self-compassion, values clarification, acceptance) and interpersonal variables (i.e. 'self in context', for example prosocial behaviour, peer problems, quality of parent-child relationship).

\section{Funding}

H.M. was supported with a publicly funded Postdoctoral Fellowship (SFRH/BPD/70063/2010). All authors are supported by the Cognitive and Behavioral Center for Research and Intervention (Faculty of Psychology and Education Sciences, University of Coimbra).

\section{Acknowledgements}

We are grateful to Professor Dr Helen McConachie (Newcastle University) for her final review of this manuscript, and to Fernanda Maurício (Cerebral Palsy Association of Coimbra) for her availability in compiling a number of clinical resources.

\section{References}

Allmond BW, Buckman W, Gofman HF (1979) The Family is the Patient: An Approach to Behavioral Pediatrics for the Clinician. Mosby Publishing.

*Baer RA (2003) Mindfulness training as a clinical intervention: a conceptual and empirical review. Clinical Psychology: Science and Practice, 10: 125-43

Bögels SM, Restifo K (2014) Mindful Parenting: A Guide for Mental Health Practitioners. Springer.

Burke CA (2010) Mindfulness-based approaches with children and adolescents: A preliminary review of current research in an emergent field. Journal of Child and Family Studies, 19: 133-44.

Carona C (2013a) The psychosocial adaptation of children and adolescents with cerebral palsy and their parents: a different matter or a matter of difference? Doctoral dissertation, Coimbra University (http://hdl.handle. net/10316/24358)

Carona C, Crespo C, Silva N, et al (2013b) Examining a developmental approach to health-related quality of life assessment: psychometric analysis of DISABKIDS generic module in a Portuguese sample. Vulnerable Children and Youth Studies, 8: 243-57.

Ciarrochi J, Bailey A (2008) A CBT-Practicioner's Guide to ACT: How to Bridge the Gap between Cognitive Behavioral Therapy and Acceptance and Commitment Therapy. New Harbinger Publications.

Ciarrochi J, Hayes L, Bailey A (2012) Get Out of Your Mind and Into Your Life for Teens: A Guide to Living an Extraordinary Life. New Harbinger Publications.

Dimidjian S, Linehan MM (2003) Defining an agenda for future research on the clinical implications of mindfulness practice. Clinical Psychology: Science and Practice, 10: 166-78.

*Duncan LG, Coatsworth JD, Greenberg MT (2009) A model of mindful parenting: implications for parent-child relationships and prevention research. Clinical Child and Family Psychology Review, 12: 255-70.

Folkman S (1997) Positive psychological states and coping with severe stress. Social Science \& Medicine, 45: 1207-21.

Greenberg MT, Harris AR (2012) Nurturing mindfulness in children and youth: current state of research. Child Development Perspectives, 6 : 161-6.

Halifax $J$ (2011) The precious necessity of compassion. Journal of Pain and Symptom Management, 41: 146-53.
MCO answers

$\begin{array}{lllll}1 d & 2 c & 3 b & 4 c & 5 a\end{array}$ 
Harnett PH, Dawe S (2012) The contribution of mindfulness-based therapies for children and families and proposed conceptual integration. Child and Adolescent Mental Health, 17: 195-208.

Harrington N, Pickles C (2009) Mindfulness and cognitive behavioral therapy: are they compatible concepts? Journal of Cognitive Psychotherapy, 23: 315-23.

*Hayes SC, Strosahl KD, Wilson KG (1999) Acceptance and Commitment Therapy: An Experiential Approach to Behavior Change. Guilford Press.

Hayes SC (2004a) Acceptance and commitment therapy, relational frame theory, and the third wave of behavioral and cognitive therapies. Behavior Therapy, 35: 639-65.

Hayes SC, Shenk C (2004b) Operationalizing mindfulness without unnecessary attachments. Clinical Psychology: Science and Practice, 11: 249-54.

Johnson J, Gooding PA, Wood AM, et al (2013) A therapeutic tool for boosting mood: the broad-minded affective coping procedure (BMAC). Cognitive Therapy and Research, 37: 61-70.

Kabat-Zinn J (1994) Wherever You Go, There You Are: Mindfulness Meditation in Everyday Life. Hyperion.

Kabat-Zinn J (2003) Mindfulness-based interventions in context: past present, and future. Clinical Psychology: Science and Practice, 10: 144-56.

Kahl KG, Winter L, Schweiger U (2012) The third wave of cognitive behavioural therapies: what is new and what is effective? Current Opinion in Psychiatry, 25: 522-8

Khoury B, Lecomte T, Fortin G, et al (2013) Mindfulness-based therapy: a comprehensive meta-analysis. Clinical Psychology Review, 33: 763-71.

Larson E (2010) Psychological well-being and meaning-making when caregiving for children with disabilities: growth through difficult times or sinking inward. OTJR: Occupation, Participation, Health, 30: 78-86.

*Linehan MM (1993) Cognitive-Behavioral Treatment of Borderline Personality Disorder. Guilford Press.

Mace C (2007) Mindfulness in psychotherapy: an introduction. Advances in Psychiatric Treatment, 13: 147-54.

Öst LG (2008) Efficacy of the third wave of behavioral therapies: a systematic review and meta-analysis. Behavior Research and Therapy, 46: $296-321$
Race K (2013) Mindful Parenting. St Martin's Griffin

Segal ZV, Williams JMG, Teasdale JD (2002) Mindfulness-Based Cognitive Therapy for Depression: A New Approach to Preventing Relapse. Guilford Press.

Semple RJ, Lee J, Miller LF (2006) Mindfulness-based cognitive therapy for children. In Mindfulness-Based Treatment Approaches: Clinician's Guide to Evidence Base and Applications (ed RA Baer): 143-66. Academic Press.

Shapiro SL, Carlson L, Astin J, et al (2006) Mechanisms of mindfulness. Journal of Clinical Psychology, 62: 373-86.

Silva N, Carona C, Crespo C, et al (2015) Caregiving burden and uplifts: a contradiction or a protective partnership for the quality of life of parents and their children with asthma? Journal of Family Psychology, 29: 151-61.

Silverton S (2012) The Mindfulness Breakthrough. Watkins Publishing.

Singh NN, Lancioni GE, Joy SDS, et al (2007) Adolescents with conduct disorder can be mindful of their aggressive behavior. Journal of Emotional and Behavioral Disorders, 15: 56-63.

Snel E (2013) Sitting Still Like a Frog: Mindfulness Exercises for Kids land Their Parents). Shambhala Publications.

Tarrier N (2010) Broad minded affective coping (BMAC): a 'positive' CBT approach to facilitating positive emotions. International Journal of Cognitive Therapy, 3: 64-76.

*Thompson M Gauntlett-Gilbert J (2008) Mindfulness with children and adolescents: effective clinical application. Clinical Child Psychology and Psychiatry, 13: 395-407

Wagner EE, Rathus JH, Miller AL (2006) Mindfulness in dialectical behavior therapy (DBT) for adolescents. In Mindfulness-Based Treatment Approaches: Clinician's Guide to Evidence Base and Applications (ed RA Baer): 167-89. Academic Press.

Wells A (2006) Detached mindfulness in cognitive therapy: a metacognitive analysis and ten techniques. Journal of Rational-Emotive and Cognitive Behavior Therapy, 23: 337-55.

Wiliams JMG (2008) Mindfulness, depression and modes of mind. Cognitive Therapy and Research, 32: 721-33.

Williams M, Penman D (2011) Mindfulness: A Practical Guide to Finding Peace in a Frantic World. Rodale.

${ }^{*}$ Asterisks denote references of particular interest.

\section{MCOs}

Select the single best option for each question stem

1 The therapeutic applications of mindfulness in paediatric settings:

a are limited to the treatment of psychological disorders

b may only be described for older patients (i.e. adolescents)

c are restricted to stress reduction programmes

$\mathrm{d}$ encompass the improvement of psychological adjustment and adaptive coping

e cannot be prescribed for chronic health conditions.

2 Mindfulness-based interventions may be recommended for parents of children/ adolescents with chronic conditions as a means of:

a distracting them from their daily hassles and burdens

b correcting their cognitive distortions c facilitating positive meaning-making

d improving their spirituality

e increasing control over aversive emotions.

3 In comparison to treatments designed for adolescents, mindfulness-based interventions for school-aged children should:

a be essentially the same, because they are all 'kids'

b include briefer exercises and more play

c be avoided, since children lack metacognitive skills

$d$ be exclusively directed to parents

e always include formal meditation exercises.

4 Which of the following is not a dimension of mindful parenting?

a exerting self-regulation in parenting relationship

b directing compassion for the self and the child c adopting a non-reactive attitude towards any problem behaviour

d listening with full attention to the child

e developing emotional awareness of the self and the child.

5 Which of the following best describes the current state for mindfulness-based interventions in paediatric settings?

a there is increasing evidence for their feasibility and efficacy

b there is only anecdotal evidence for their efficacy in children

c there is only reliable evidence for their efficacy in adults

$d$ there is no empirical evidence for the efficacy of mindful parenting programmes

e there is evidence for their feasibility, but not for their efficacy. 